Review

\title{
SNPs Array Karyotyping in Non-Hodgkin Lymphoma
}

\author{
Maryam Etebari, Mohsen Navari and Pier Paolo Piccaluga * \\ Department of Experimental, Diagnostic, and Specialty Medicine; Bologna University School of \\ Medicine; Hematopathology Unit, S. Orsola-Malpighi Hospital, Bologna 40138, Italy; \\ E-Mails: maryam.etebari@gmail.com (M.E.); mohsen.navari@gmail.com (M.N.) \\ * Author to whom correspondence should be addressed; E-Mail: pierpaolo.piccaluga@unibo.it; \\ Tel.: +39-051-214-4043; Fax: +39-051-214-4037.
}

Academic Editor: Jari Louhelainen

Received: 19 August 2015 / Accepted: 4 November 2015 / Published: 12 November 2015

\begin{abstract}
The traditional methods for detection of chromosomal aberrations, which included cytogenetic or gene candidate solutions, suffered from low sensitivity or the need for previous knowledge of the target regions of the genome. With the advent of single nucleotide polymorphism (SNP) arrays, genome screening at global level in order to find chromosomal aberrations like copy number variants, DNA amplifications, deletions, and also loss of heterozygosity became feasible. In this review, we present an update of the knowledge, gained by SNPs arrays, of the genomic complexity of the most important subtypes of non-Hodgkin lymphomas.
\end{abstract}

Keywords: non-Hodgkin lymphoma; single nucleotide polymorphism (SNP) array; genetic aberrations

\section{Introduction}

Non-Hodgkin lymphomas (NHL) are a heterogeneous group of malignancies that originate from the lymphatic system and, in particular, from either immature or mature/peripheral lymphocytes [1]. Their classification is primarily based on the cell of origin (i.e., B or T cell) or histogenesis, which is further narrowed into different categories based on morphology, phenotype, genetic and clinical characteristics. Therefore, the diverse types of NHL significantly vary in both their clinical features, being defined as either indolent or aggressive, and pathobiology. As far as the latter is concerned, in the last decade tremendous advances have been made in the understanding of the molecular pathogenesis of lymphomas 
leading in some instances to a real molecular classification, as in the case of diffuse large B-cell lymphomas (DLBCL) (see below) [2].

Genetic aberrations, such as copy number variants (CNVs) and translocations have been shown to be specifically correlated with certain human cancers and, quite often, with hematological malignancies including lymphomas. In this regard, various technological advances in molecular analyses have greatly enhanced our ability to identify specific genetic aberrations in any tumor type [3]. In particular, the introduction of high-throughput technologies such as microarrays allowed fast and relatively cheap extensive studies leading to the discovery of several genetic aberrations [3]. Importantly, their identification has a practical impact, having an important role in diagnosis, prognosis, and subsequent choice of therapy in cancers [4-8].

Traditionally, genomic lesions in cancer specimens have been recognized using metaphase cytogenetic (MC), fluorescent in situ hybridization (FISH) and Sanger sequencing. However, though still relevant, these methods impose several limitations like the dependence on the availability of dividing cells and resolution restrictions (MC) [9]. Albeit the abilities of FISH and sequencing in triumphing over some of the above mentioned disadvantages like the lack of dependency upon dividing cells, they are limited in terms of being applicable to the candidate regions, making them unsuitable for the genome-wide screenings [10].

These drawbacks were further overcome with the introduction of high resolution methods such as comparative genomic hybridization $(\mathrm{CGH})$ and SNP microarrays, enabling us with genome-wide molecular karyotyping possibilities. Besides the lack of need for dividing cells, above all SNP arrays provide us with the opportunity of the detection of several types of genetic lesions, by progressively expanding the resolution of DNA analysis (explained below) [11-16].

Here, we highlighted the most recent findings obtained from global analysis of genetic aberrations in some of the most common subtypes of NHL of B- and T-cell origin, including DLBCL, follicular lymphoma (FL), mantel cell lymphoma (MCL), marginal zone B cell lymphoma (MZL), and peripheral T cell lymphomas (PTCLs).

\section{Single Nucleotide Polymorphism (SNP) Array and Its Applications}

Single nucleotide polymorphisms (SNPs) are defined as variations of a DNA sequence at single nucleotide level which are found in a high proportion of human genome (i.e., more than 1\%). SNPs might occur in any position in the genome. These polymorphisms have a wide effect on human health, ranging from disease development to response to the therapies [17]. Thus, technologies like SNP arrays were recently applied in order to screen the genome at global level allowing to better define correlations between genetic patterns and phenotypes, including diseases [17,18].

Several different companies offer the related technology. However, as far as the experience in human lymphomas is concerned, two of them (i.e., Affymetrix, Santa Clara, CA, USA and Illumina, San Diego, CA, USA) demonstrated their leadership, offering arrays characterized by high reliability and reproducibility. Of note, the two technologies, albeit being based on different chemistries, show some common features [19]. Basically, a microarray/chip harboring unique probes for each SNP is prepared. The target DNA is then fragmented, labeled and hybridized to the probes present on the chip. A potential binding between the target DNA and the SNP probe is evaluated based on the intensity of the signal, which 
could provide the researcher with the information about the copy number state and the genotype [20-23]. As a result, genetic imbalances such as copy number variants (CNVs) and loss or gain of heterozygosity ( $\mathrm{LOH}$ and $\mathrm{GOH}$, respectively) can easily be detected [24-29]. Particularly, besides resolution, the latter cannot be identified by MC. In fact, LOH is generally caused by monoallelic deletions, the lost segment being then replaced by the same region of its homologous chromosome, resulting in a so called copy neutral loss of heterozygosity (CN-LOH) or uniparental disomy (UPD) [18,30-32]. The acquired homozygosity resulting from UPD could lead to development of tumors, as largely indicated by SNPs array-based studies [33,34].

\section{SNP Array Analysis in Non-Hodgkin Lymphoma}

\subsection{Diffuse Large B Cell Lymphoma}

Diffuse large B-cell lymphoma (DLBCL) is the most frequent NHL subtype, accounting for about $30 \%$ of all lymphoma cases worldwide. Although overall presenting as a unique entity, with the usage of gene expression profiling, it turned out that DLBCL is constituted by at least two distinct subtypes: germinal center B-cell like (GCB-DLBCL) and activated B-cell like (ABC-DLBCL) [2]. Furthermore, a third group of DLBCL cases exists, which have been defined as "gray zone", which are not classifiable as either ABD or GCB subtypes [35].

In 2003, Wessendorf et al. [36] first demonstrated that increasing sensitivity of cytogenetic analysis by matrix comparative genomic hybridization (M-CGH) could allow to detect previously uncovered lesions in DLBCL and other aggressive lymphoma specimens. Among others, the authors identified small amplifications affecting genes involved in lymphoma pathogenesis such as BCL2, REL, CCND1, $C C N D 2, J A K 2, F G F 4$ and MDM2. This basic evidence prompted further research toward more and more sensitive tools. Since then, in fact, several studies have been carried out using SNP arrays alone or in combination with other methods to uncover unidentified genes involved in DLBCL (Table 1) [37-48]. While some features, e.g., gains on chromosome 7, are common between the two subtypes, many others such as gains on chromosomes 1, 7, 12, 3, 18, 2, 19 and 13 and losses on chromosomes 9, 6, 7, 15 and 17 might affect the differences between the two subtypes. Among the affected genes by gains, $R E L$, $B C L 2, B C L 11 A$ and mir-17, and among the affected genes by losses PTEN, PRDM1, TP53, TNFAIP3, $J A K 2, B A C H 2, C A S P 8 A P 2, H D A C 7 A$ and $F A S$ are worth to mention [37-48].

As far as the differences between the two subtypes of DLBCL are concerned, Scholtysi et al. [43] conducted a study mainly focused on the matter, analyzing 148 primary tumors (including 79 GCB-DLBCL, 49 ABC-DLBCL and 20 unclassified cases) [42,43]. Collectively, they found 24 and 38 regions of recurrent gains and losses and 38 regions of recurrent genomic losses, respectively, averaging 25 and 19 imbalances per case for ABC-DLBCL and GCB-DLBCL, respectively. Among them, a recurrent deletion was found in 19p13.3 in several primary cases, which included two members of Tumor Necrosis Factor superfamily, namely TNFSF7 and TNFSF9. Furthermore, they identified several copy number variations with substantially differential frequencies among the two subtypes of DLBCL. For example, a loss on chromosome 9 (a region covering tumor suppressor genes $C D K N 2 A$ and $C D K N 2 B$ ) was found in $46.9 \%$ of ABC-DLBCL cases, while the occurrence of this loss in GCB-DLBCLs was only $12.7 \%$. Other examples include gain on chromosome 2 (including REL and BCL11A genes) with an occurrence 
rate of $10.2 \%$ and $30.4 \%$ for ABC- and GCB-DLBCL, respectively, gains of HDAC7A on chromosome 12 mainly observed in GCB-DLBCL (38\% of cases as compared to $14.3 \%$ in ABC-DLBCL) and predominant losses of $B A C H 2$ and CASP8AP2 ABC-DLBCL (34.7\% vs. 20.3\% in GCB subtype) [42,43].

Table 1. The most important recurrent genetic aberrations in diffuse large B-cell lymphoma (DLBCL), as discussed in the text.

\begin{tabular}{|c|c|c|c|}
\hline Location & Alteration & Candidate Genes & References \\
\hline $1 \mathrm{q}$ & Gain & $C D 58$ & {$[38,42,47]$} \\
\hline 2 & Gain & $R E L, B C L 11 A$ & {$[37,38,40-42,49]$} \\
\hline 3 & Gain & FOXP1 & {$[42,45]$} \\
\hline $6 q 15$ & Loss & BACH2, CASP $8 A P 2$ & {$[39,42]$} \\
\hline $6 \mathrm{q} 21$ & Loss & PRDMI & {$[38,42]$} \\
\hline $6 \mathrm{q} 23$ & Loss & TNFAIP3 (A20), MAP3K5 & {$[38,42,47]$} \\
\hline 7 & Gain, Loss & - & [37-39] \\
\hline $8 \mathrm{p}$ & Loss & - & [41] \\
\hline $9 \mathrm{p} 21$ & Loss & $C D K N 2 A, C D K N 2 B$ & {$[38,47,49]$} \\
\hline 9 p24 & Gain & $J A K 2$ & [47] \\
\hline $9 q 34$ & Gain & NOTCH1 & [47] \\
\hline 9 & Loss & $I N K 4 a / A R F$ & [45] \\
\hline $10 q$ & Loss & FAS, PTEN & {$[38,40,45,47]$} \\
\hline 10 & Loss & PTEN & {$[45]$} \\
\hline $11 \mathrm{p} 11$ & $\mathrm{LOH}$ & PTPRJ & [46] \\
\hline $11 \mathrm{q} 25$ & Gain & LOC283177 & [48] \\
\hline 12 & Gain & $C D K N 1 B$ & [49] \\
\hline $12 \mathrm{p} 13$ & Gain & FOXM1 & [40] \\
\hline $12 \mathrm{q} 13$ & Gain & $M A P 3 K 12$ & [40] \\
\hline $12 q$ & Gain & $H D A C 7 A$ & {$[37,42]$} \\
\hline 13 & Gain & mir-17-92 & [45] \\
\hline $13 \mathrm{q} 14$ & Gain, Loss & $R B 1$ & {$[38,49]$} \\
\hline 15 & Loss & $53 B P 1$ & {$[42,44]$} \\
\hline $17 \mathrm{p}$ & Loss & TP53 & {$[37,38,40,42,49]$} \\
\hline $18 \mathrm{q} 21$ & Gain & $B C L 2$ & {$[37,38,42,49]$} \\
\hline $19 \mathrm{p} 13$ & Loss & TNFSF7, TNFSF9, CD70 & {$[38,40,42]$} \\
\hline $19 \mathrm{q} 13$ & Gain & PRMT1, BCL2L12 & [38] \\
\hline
\end{tabular}

Very recently, Dias et al. [47] used an intercross of public datasets from three different platform types (i.e., SNP array, CGH array and Gene expression Profiling) to analyze 392 DLBCL samples, looking for the $\mathrm{CNV}$ associated with the differential gene expression levels. Among the abnormal genomic regions identified by them, 32 turned out to be overlapped between at least two datasets. Based on the data, they defined 36 minimal common regions (MCR), several of which overlapped with peaks defined by GISTIC program, among which gains on 2p16.3-p14 (REL) and 9q34.11-q34.3 (NOTCH1) and losses on 1p13.2-p12 (CD58), 6p12.3-q27 (TNFAIP3), 9p24.3-p21.1 (JAK2, CDKN2A), 10q23.2-23.32 (FAS) and 19p13.3-p13.2 (CD70) can be mentioned [47]. 
As expected, SNP arrays have helped to define better the possible role of human genes in malignancies. For example, a locus in chromosomal location 15q15 encoding for p53-Binding protein 1 (53BPl), the protein product of which has a major role in DNA double strand break repair, was reported to be a subject of single copy loss in 9 out of $63(14.5 \%)$ cases of DLBCL, as indicated by Takeyama et al. [44]. Interestingly, the same authors found a significant decrease in the gene expression level of 53BPI in the related tumor cases, indicating for the first time a possible role of this gene in human malignancies. Of note, this was the first report of such a role in human tumors [44]. Furthermore, although analyzing a limited number of DLBCL cases $(n=18)$, by combining SNP array technology and transcriptome profiling, Green et al. [40] found genetic lesions that significantly enriched for apoptosis and the mitogen activated protein kinase pathways. They were able to recognize two recurrent amplifications in DLBCL primary tumors, including 12p13.33 targeting FOXM1 and 12q13.13, targeting MAP3K12. The authors argued the possible role of FOXM1 in non-hodgkin lymphomagenesis, demonstrating its possible association an increased MYC oncogenic signaling signature [40]. In another study on 242 DLBCL cases, Conde et al. [48] found a duplication for the chromosomal region 11q25 in $6.2 \%$ of cases. Interestingly, this region encodes for a long non-coding RNA (LOC283177), which further highlights the accumulating evidences for the role of this family of RNAs in human diseases.

Remarkably, some CNV patterns appeared significantly related with treatment response (when R-CHOP was considered as therapy) and overall survival $[38,41,45,49]$. Specifically, first of all, based on a study on 203 samples, the LMPP (Leukemia/Lymphoma Molecular Profiling Project) provided the genetic evidence that ABC- and GCB-DLBCL are distinct. In fact, they identified 272 recurrent chromosomal aberrations associated with gene expression alterations, 30 of which could efficiently separate the two DLBCL subtypes $(p<0.006)$ [45]. Among them, an amplicon on chromosome 19 was detected in $26 \%$ of ABC-DLBCLs but in only $3 \%$ of GCB-DLBCLs. A highly up-regulated gene in this amplicon was $S P I B$, which encodes an ETS family transcription factor and which was later on functionally related the pathogenesis of ABC-DLBCL. Similarly, Deletion of the INK4a/ARF tumor suppressor locus and trisomy 3 (leading to the over-expression of FOXPl) also occurred almost exclusively in ABC-DLBCLs and were associated with inferior outcome within this subtype. By contrast, in GCB-DLBCL, amplification of the oncogenic miR-17-92 microRNA cluster and deletion of the tumor suppressor PTEN were recurrent, but were not observed in the ABC-subtype [45].

Subsequently, Scandurra et al. [41] studied 166 primary samples and identified 20 recurrent genetic lesions that showed an impact on the clinical course. Among them, lesions with the strongest association with a worse outcome were deletions affecting the short arm of chromosome 8 , including del(8p23.1) $(p=0.002), \operatorname{del}(8 \mathrm{p})(p=0.01)$, and $\operatorname{del}(8 \mathrm{p} 23.1-21.2)(p=0.012)$. The loss of genomic material at $8 \mathrm{p} 23.1$ also appeared to be associated with additional aberrations, such as $17 \mathrm{p}$ - and $15 \mathrm{q}-$. Overall, seven pathways appeared to be significantly enriched within the loci affected by CNV associated with survival: regulation of autophagy, natural killer cell-mediated cytotoxicity, antigen processing and presentation, Toll-like receptor signaling pathway, JAK-STAT signaling pathway, apoptosis and cytokine-cytokine receptor interaction. Finally, unsupervised clustering identified five DLBCL clusters with distinct genetic profiles, clinical characteristics (e.g., bone marrow involvement) and outcomes [41]. In another study performed by the GELA group, it was found that losses of TP53 and CDKN2A, observed in 8\% and 35\% of 114 DLBCL patients analyzed, respectively, were significantly associated with a shorter survival after R-CHOP treatment, independently of the International Prognostic Index [49]. Analysis of the 9p21 
genomic region indicated that transcripts encoding p14ARF and p16INK4A were both disrupted in most patients with $C D K N 2 A$ deletion. These patients predominantly had an $\mathrm{ABC}$-profile and showed a specific gene expression signature, characterized by deregulation of the RB/E2F pathway, activation of cellular metabolism, and decreased immune and inflammatory responses [49]. More recently, Monti et al. [38] studies 180 primary cases and showed that DLBCL cases showed either multiple complementary alterations of TP53 and cell cycle components or largely lacked such lesions. DLBCLs with TP53 and cell cycle pathway copy number abnormalities had decreased abundance of p53 transcriptional targets and increased expression of E2F target genes as well as increased Ki67 proliferation marker and poor clinical outcome [38].

Finally, some frequent regions showing LOH, including $11 \mathrm{p} 11.2$ have been identified in DLBCL cases. The latter which affects $P T P R J$, was reported in 38\% (16/42) of primary DLBCLs, indicating the LOH (and possible subsequent inactivation) of PTPRJ as a recurring event in NHLs [46].

\subsection{Follicular Lymphoma}

Follicular lymphoma (FL) is the second most common NHL subtype worldwide and possibly the most common in USA. Despite the clear differences in tumor biology, morphology, and aggressiveness when compared to DLBCL [50,51], there are some common molecular pathogenetic mechanisms among the two tumors, and more notably, by gaining new genomic aberrancies, at least $20 \%$ of FLs convert to DLBCL during time $[40,52,53]$. The most frequent genetic aberrancy in FL is a $\mathrm{t}(14 ; 18)(\mathrm{q} 32 ; \mathrm{q} 21)$ translocation, which is observed in about $90 \%$ of cases and causes an over-expression of $B C L 2$, an important antiapoptotic molecule [54]. However, BCL2 translocation is not sufficient for FL development. Furthermore, a small minority of cases lack this translocation possibly representing a genetically different subset; in fact, by SNPs array analysis it was documented that BCL2-negative FL is characterized by a more simple genomic profile than the classical BCL2-positive ones [55].

In 2010, by using a multiplatform approach, including conventional cytogenetic techniques, BAC array comparative genomic hybridization, and Affymetrix 500K SNP arrays, Cheung et al. [56] studied a series of $50 \mathrm{FL}$ cases for which normal matched DNA was available. This approach allowed to identify, in addition to the $\mathrm{t}(14 ; 18)$, eight unique balanced translocations, including $\mathrm{t}(1 ; 11 ; 3), \mathrm{t}(3 ; 16)(\mathrm{q} 27 ; \mathrm{p} 13)$, $\mathrm{t}(2 ; 4)(\mathrm{p} 16 ; \mathrm{q} 28)$ and $\mathrm{t}(2 ; 4)$. The previously reported FL-associated copy number regions identified in their study were revealed including losses of 1p32-36, 6q, and 10q, and gains of 1q, 6p, 7, 12, 18, and X. The most frequent regions affected by CN-LOH turned out to be $1 \mathrm{p} 36.33$ (28\% of cases), 6p21.3 (20\%), 12q21.2-q24.33 (16\%), and 16p13.3 (24\%). Such regions were similarly affected in cases with more or less complex karyotype [56,57]. Of interest, the high resolution of the SNPs array allowed to identify 45 aberrant regions affecting one gene each, including CDKN2A, CDKN2B, FHIT, KIT, PEX14, and PTPRD (Table 2) [56]. 
Table 2. The most important recurrent genetic aberrations in Follicular Lymphoma (FL).

\begin{tabular}{|c|c|c|c|}
\hline Location & Alteration & Candidate Genes & References \\
\hline $1 \mathrm{p} 32-36$ & Loss & - & [56] \\
\hline $1 \mathrm{p} 36$ & Loss & TNFRSF 14, PRDM16 & {$[58,59]$} \\
\hline $1 \mathrm{p} 36.22$ & Gain & PEX14 & {$[56]$} \\
\hline $1 \mathrm{p} 36.33$ & Gain & TNFRSF14 & [59] \\
\hline $1 \mathrm{p} 36$ & CN-LOH & TNFRSF 14, PRDM16 & {$[56-58,60,61]$} \\
\hline $1 \mathrm{q}$ & Gain & - & {$[56]$} \\
\hline $2 \mathrm{p} 16$ & Gain & $R E L, B C L 11 A$ & [59] \\
\hline $3 \mathrm{p} 14$ & Loss, Gain & FHIT & [56] \\
\hline $3 \mathrm{q} 27 *$ & Gain & BCL6 & [59] \\
\hline $4 q 12$ & Loss, Gain & KIT & [56] \\
\hline $5 p$ & Gain & - & {$[58,59]$} \\
\hline $6 \mathrm{p}$ & Gain & $C C N D 3$ & {$[56,58,59]$} \\
\hline $6 \mathrm{p}$ & CN-LOH & - & {$[56,57,60-62]$} \\
\hline $6 q$ & Loss & TNFAIP3 & {$[56,58,59]$} \\
\hline $6 q$ & CN-LOH & - & {$[60,61]$} \\
\hline $7 \mathrm{p}$ & Gain & $C A R D 11, R N F 216$ & {$[56,59]$} \\
\hline $8 \mathrm{q} 24$ & Gain & $M Y C$ & [59] \\
\hline $9 \mathrm{p} 21 *$ & Loss & $C D K N 2 A / 2 B$ & {$[56,59]$} \\
\hline $9 p$ & Loss & $P T P R D$ & {$[56]$} \\
\hline $10 \mathrm{q} 24$ & Loss & $L C O R$ & {$[56,59]$} \\
\hline $10 q$ & CN-LOH & - & {$[60,61]$} \\
\hline $11 *$ & Gain & - & [59] \\
\hline $11 \mathrm{p} 11$ & $\mathrm{LOH}$ & PTPRJ & [46] \\
\hline $12 q$ & Gain & $\begin{array}{c}A R I D 2, H D A C 7 \\
R P A P 3\end{array}$ & {$[56,58,59]$} \\
\hline $12 q$ & CN-LOH & - & {$[56,57,60-62]$} \\
\hline $15 \mathrm{q} 21 *$ & Loss & $B 2 M$ & [59] \\
\hline $16 p$ & $\mathrm{CN}-\mathrm{LOH}$ & - & {$[56,57,60,61]$} \\
\hline $17 \mathrm{p} 13$ & Loss & TP53 & [59] \\
\hline $17 q$ & Gain & - & [59] \\
\hline $18 \mathrm{q} 21$ & Gain & $M A L T 1, B C L 2$ & {$[56,59]$} \\
\hline 21 & Gain & - & [59] \\
\hline $\mathrm{X}$ & Gain & - & {$[56,59]$} \\
\hline
\end{tabular}

* These aberrations occur in transformed follicular lymphoma (tFL).

Several other studies have pointed at the recurrence of CN-LOH in FL, and the regions influenced include 1p36, 6p, 6q, 10q, 12q and 16p [58,60-62], which in case of acquired UPD on 1p36 and 16p were correlated with shorter overall survival and poorer progression-free survival for the former and latter, respectively [61]. In another study, the recurrent CNVs in FL were reported to be overall associated with Wnt/b-catenin signaling and G1/S checkpoint regulation [63]. Furthermore, FL showed LOH of PTPRJ gene associated with LOH of $11 \mathrm{p} 11.2$ as it was observed in DLBCL [46]. In this regard, importantly, SNPs array karyotyping was recently used to dissect the genetic imbalances associated with FL transformation to DLBCL [59]. With this aim, Bouska et al. [59] studied 277 lymphoma samples (198 FL and 79 transformed FL/tFL) by both SNPs and gene expression microarrays. Common recurrent 
chromosomal abnormalities in FL included gains of 2, 5, 7, 6p, 8, 12, 17q, 18, 21, and X and losses on $6 q$ and $17 p$. Many frequent small abnormalities, including losses of $1 \mathrm{p} 36.33-\mathrm{p} 36.31,6 \mathrm{q} 23.3-\mathrm{q} 24.1$, and 10q23.1-q25.1 and gains of 2p16.1-p15, 8q24.13-q24.3, and 12q12-q13.13 were also observed. Noteworthy, several candidate genes that may be affected were identified, including TNFRSF14, PRDM16, and the p53-family member TP73 (Table 2). Recurrent abnormalities more frequent in tFL samples included gains of 3q27.3-q28 and chromosome 11 and losses of 9p21.3 and 15q. Overall, abnormalities associated with disease transformation appeared to impair immune surveillance, activate the NFкB pathway, and deregulate p53 and B-cell transcription factors. A total of four abnormalities, namely gain of X or Xp and losses of 6q23.2-24.1 or 6q13-15, were found to be of clinical importance, i.e., were significantly associated with an overall poor survival [59].

\subsection{Mantle Cell Lymphoma}

Mantle cell lymphoma (MCL) is a neoplasm of mature B-lymphocytes with characteristic $\mathrm{t}(11 ; 14)$ (q13;q32) and subsequent CCND1 (encoding for the cyclin D1) overexpression. Despite these unifying features, MCL represents a heterogeneous disorder, ranging from indolent MCL with benign clinical course to highly aggressive variants, sometimes characterized by peculiar blastoid or pleomorphic morphology $[64,65]$. As mentioned, the $t(11 ; 14)(\mathrm{q} 13 ; \mathrm{q} 32)$ with deregulated cyclin D1 expression is the primary genomic alteration in MCL. However, this aberration is not sufficient for lymphomagenesis [66,67], additional events being requested. Importantly, SNPs array karyotyping clearly indicated that the acquisition of a more complex karyotype is associated with a more aggressive clinical behavior. In particular, on the clinical point of view, the main diagnostic issue is to distinguish the indolent subtype vs. the classical (more aggressive) subtype. While indolent MCL usually shows stable genome without many secondary chromosomal abnormalities other than $\mathrm{t}(11 ; 14)(\mathrm{q} 13 ; \mathrm{q} 32)$, classical MCL, and specially those characterized by blastoid and pleomorphic morphology, typically exhibit a complex karyotype with highly unstable genome [68,69]. Cytogenetic studies with comparative genomic hybridization microarray $(\mathrm{CGH})$ have revealed frequent secondary gains and losses, involving genes important for genomic stability, proliferation, and apoptosis, such as TP53, ATM, MYC, BMI1, CDK4 and BCL2 [68-70] (Table 3). Among the large numbers of genes implicated in the lymphomagenesis of MCL, MYC appears to play an important role in transforming the initial B-cell clone harboring $\mathrm{t}(11 ; 14)(\mathrm{q} 13 ; \mathrm{q} 32)$. MCL with both $C C N D 1$ and $M Y C$ gene rearrangements is specified as "double hit" MCL [71]. In addition to $M Y C$, other genes are also likely to be implicated in the aggressive behavior of lymphoma cells in double hit MCL. CDKN2A gene on chromosome 9 encodes two proteins by alternative splicing, INK4A and ARF, which are important in cell cycle control and stability of p53 respectively. Rubio-Moscardo et al. [72] showed that deletions of INK4a gene were associated with poorer prognosis together with blastoid morphology, increased number of genomic gains, and TP53 gene deletion. Based on these findings, assessment of the $C D K N 2 A$ gene locus in double hit MCL pathogenesis will be important in future studies as $C D K N 2 A$ gene deletion might play a role in the pathogenesis of double hit MCL [71]. Finally, another high resolution SNPs array based study identified a duplication/amplification that occurred at $13 \mathrm{q}$ involving the oncogenic microRNA, miR17-92, the same previously observed to be deregulated in DLBCL (see above) (Table 3) [73]. 
Table 3. The most important recurrent genetic aberrations in Mantle cell lymphoma (MCL).

\begin{tabular}{cccc}
\hline Location & Alteration & Candidate Genes & References \\
\hline $1 \mathrm{p}$ & Loss & - & {$[70]$} \\
$3 \mathrm{q}$ & Gain & SIAH2, PIK3CA, ACTL6A, YEATS2, RFC4, CENTB2, PAK2 & {$[68,70]$} \\
$8 \mathrm{p}$ & Loss & $E S C O 2, C L U, T N F R S F 10 D, A S A H 1$ & {$[70]$} \\
$8 \mathrm{q}$ & Gain & $M Y C$ & {$[68-70]$} \\
$9 \mathrm{p}$ & Loss & $C D K N 2 A, I N K 4 a$ & {$[68,70]$} \\
$9 \mathrm{q}$ & Loss & FANCC, XPA, RAD23 & {$[70]$} \\
$10 \mathrm{p}$ & Gain & $B M I 1$ & {$[69]$} \\
$11 \mathrm{q}$ & Loss & ATM, CASP1, CASP4, BIRC2 & {$[68-70]$} \\
$12 \mathrm{q}$ & Gain & $C D K 4$ & {$[69]$} \\
$13 \mathrm{q}$ & Loss & $E R C C 5, L I G 4$ & {$[68,70]$} \\
$13 \mathrm{q}$ & Gain & $m i R 17-92$ & {$[73]$} \\
$15 \mathrm{q}$ & Gain & - & {$[70]$} \\
$17 \mathrm{p}$ & Loss & $T P 53$ & {$[68-70]$} \\
$18 \mathrm{q}$ & Gain & $B C L 2$ & {$[69]$} \\
\hline
\end{tabular}

\subsection{Marginal Zone Lymphomas}

Marginal zone B-cell lymphomas (MZLs) are currently divided into three distinct subtypes (extranodal MZLs of mucosa-associated lymphoid tissue (MALT) type, nodal MZLs, and splenic MZLs) according to the WHO Classification. However, the pathobiological differences as well as the relationship between the subtypes are still not well defined. In 2011, Rinaldi et al. [74] performed an extensive genomic analysis of DNA copy number changes in a large series of MZL cases, aiming to identify differences among subtypes. To do this, the Authors applied the Affymetrix Human Mapping 250K SNP array to 218 MZL samples (25 nodal, 57 MALT, 134 splenic, and two not better specified MZLs). First, it was found that MALT lymphoma presented significantly more frequently gains at $3 p$, $6 \mathrm{p}, 18 \mathrm{p}$, and $\operatorname{del}(6 \mathrm{q} 23)(T N F A I P 3 / A 20)$. The latter finding, as A20 is a negative regulator of the NFKB pathway, was consistent with the activation of this pathway that is a frequent event in MALT lymphoma, more often due to chromosomal translocations. On the other hand, splenic MZLs was associated with $\operatorname{del}(7 q 31)$ and del(8p). Nodal MZLs lacked the splenic MZLs-related 7q losses but it did not show any statistically significant difference when compared with MALT lymphoma. Gains of $3 q$ and $18 \mathrm{q}$ were common to all subtypes, confirming the existence of common pathogenetic pathways in the three variants (Table 4). From a clinical perspective, though del(17p), affecting TP53, did not determine a significantly worse outcome and del $(8 \mathrm{p})$ was only of borderline significance, the presence of both deletions (indeed often associated) had a highly significant negative impact on the outcome of splenic MZLs [74]. 
Table 4. The most important recurrent genetic aberrations in Marginal zone B-cell lymphomas (MZLs).

\begin{tabular}{|c|c|c|c|c|}
\hline Malignancy & Location & Alteration & Candidate Genes & References \\
\hline \multirow{2}{*}{ MZL (all 3 subtypes) } & $3 q$ & Gain & NFKBIZ, BCL6 & {$[74]$} \\
\hline & $18 \mathrm{q}$ & Gain & BCL2, NFATC1 & [74] \\
\hline \multirow{19}{*}{ MALT* } & $2 \mathrm{p} 15$ & Gain & $R E L, B C L 11 A$ & [75] \\
\hline & $3 p$ & Gain & FOXP1 & [74] \\
\hline & $6 p$ & Gain & - & [74] \\
\hline & $6 q 23$ & Loss & TNFAIP3/A20 & [74] \\
\hline & $8 \mathrm{p} 11$ & Gain-Loss & $A D A M 3 A$ & [75] \\
\hline & $10 q 23$ & Gain & PTEN & [75] \\
\hline & $11 \mathrm{q} 24$ & Gain & ETS1 & [75] \\
\hline & $12 \mathrm{p} 12$ & Gain & $K R A S$ & [75] \\
\hline & $15 \mathrm{q} 24$ & Gain-Loss & SCAPER & [75] \\
\hline & $18 \mathrm{p}$ & Gain & - & [74] \\
\hline & $20 \mathrm{p} 13$ & Gain-Loss & SIRPBI & [75] \\
\hline & $20 \mathrm{q} 13$ & Gain & PTPN1 & [75] \\
\hline & $1 \mathrm{p} 34$ & aUPD & PRDXI, MUTYH & [75] \\
\hline & $1 \mathrm{p} 36.11-12$ & aUPD & $E 2 F 2, A S A P 3$ & [75] \\
\hline & $1 q 43-q 44$ & aUPD & $A K T 3$ & [75] \\
\hline & $2 p 23-24$ & aUPD & TP53I3 & [75] \\
\hline & $6 q 21$ & aUPD & TRAF3IP $2, F Y N$ & [75] \\
\hline & $17 q 12$ & aUPD & $M E D 1, E R B B 2, G R B 7, I K Z F 3$ & [75] \\
\hline & $17 q 23-24$ & aUPD & PECAM1/CD31 & {$[75]$} \\
\hline \multirow{3}{*}{ Splenic MZL } & $7 q$ & Loss & POT1, MIR29A, MIR29B & {$[74]$} \\
\hline & $8 \mathrm{p}$ & Loss & - & {$[74]$} \\
\hline & $17 \mathrm{p}$ & Loss & TP53 & {$[74]$} \\
\hline \multirow{5}{*}{$\begin{array}{l}\text { Ocular adnexal } \\
\text { MALT }\end{array}$} & $6 \mathrm{p}$ & Gain & - & {$[76]$} \\
\hline & $6 q$ & Loss & - & {$[76]$} \\
\hline & $9 \mathrm{p}$ & Loss & - & [76] \\
\hline & $21 \mathrm{q}$ & Gain & - & {$[76]$} \\
\hline & $6 \mathrm{q}$ & aUPD & - & [76] \\
\hline
\end{tabular}

*MALT: mucosa-associated lymphoid tissue.

More recently, another group focused on MALT lymphomas, aiming to identify by SNPs array karyotyping, possible genomic changes associated with disease progression [75]. Indeed, they included seven cases characterized by small cell morphology, eight composite lymphomas (i.e., cases with small cell morphology and areas constituted by large cells) and 13 large cell variants using the Affymetrix Genome-Wide Human SNP Array 6.0 array. Consistent with the initial hypothesis, the Authors found an increase of genomic complexity with lymphoma progression from small to large cytology, and identified gains of well known oncogenes, including REL, BCL11A, ETS1, PTPN1, PTEN and KRAS, which were found exclusively in the large cell variants (Table 4). Copy numbers of $A D A M 3 A, S C A P E R$ and SIRPBI also varied among the three cytological subtypes, again indicating the presence of aberrations associated with progression from small to large cell lymphoma. Interestingly, the observation that the number of aberrations was slightly higher in the large cell part of composite lymphomas as 
compared to large cell lymphomas raised the hypothesis that large cells areas within composite lymphomas may represent a transition state of clonal selection during the progression from small cell to large cell variants. In line with this, when the cytologically different portions of two cases were analyzed in depth, an increase of genomic complexity from the small cell to the more blastoid part of the lymphoma was observed [75]. Interestingly, SNPs array analysis highlighted the frequency of acquired UPD in MZL, a previously uncovered phenomenon [74,75]. Among other loci, aUPD interested regions containing PECAM1/CD31, PRDX1, E2F2, AKT3, and TRAF3IP2 (Table 4) [75]. Furthermore, a very recent analysis of 29 ocular adnexal MALT lymphomas, as reported by Takahashi et al. [76], revealed a higher occurrence rate of gains, as compared to losses and UPDs. Indeed, the authors reported gains including trisomy 3 in $31 \%$ of cases, trisomy 18 identified in $17 \%$ of samples, and $6 \mathrm{p}$ and $21 \mathrm{q}$ in $14 \%$ of tumors. On the other hand, losses of $6 q$ and $9 p$ were detected in $7 \%$ of all cases, along with UPD of $6 \mathrm{q}$ in $14 \%$ of cases.

\subsection{Peripheral T Cell Lymphomas}

Peripheral T cell lymphomas (PTCLs) are a heterogeneous group of cancers characterized by extremely variable morphology, phenotype, genetic and clinical features. The latter, however, mainly consist in very aggressive behavior and poor clinical outcome for most nodal tumors [77,78]. As the majority of PTCLs cannot be currently classified within a specific group based on morphology, phenotype, genetics and clinical features, they were included within the not otherwise specified group (PTCL/NOS) [79]. The latter, together with angioimmunoblastic T-cell lymphoma (AITL) and anaplastic large cell lymphomas (ALCL) ALK-positive and ALK-negative, represent the commonest nodal PTCL. Probably due to their rarity in Western countries, where they account for not more than $10 \%$ of all NHL, only relatively few genomic studies have been performed in this setting, specially based on SNPs arrays [80-82]. In 2008, Fujiwara et al. [80] used a GeneChip 50k SNP array to evaluate genetic perturbations in PTCL/NOS and AITL. They recognized some recurrent gains and losses, with chromosomal regions $8 \mathrm{q} 24,9 \mathrm{p} 23$ and 19q13 for the former and 9p21 for the latter (Table 5). Interestingly, the recurrent loss mapped to $C D K N 2 A$ and $C D K N 2 B$, two important inhibitors of cyclin-dependent kinases with established role in human cancers. Subsequently, our group, by using the Affymetrix 250k GeneChip SNP array could achieve a higher resolution in defining the recurrent CNV and provided some additional details as far PTCL/NOS were concerned [81]. Indeed, we recognized a set of recurrent imbalances, including gains on chromosome 1, 2, 7, 8, 11, 17 and 21, and losses on chromosomes 1, 5, 6, 8, 9, 10, $13,15,16,17$ and $\mathrm{X}$ chromosome. Interestingly, genomic imbalances affected several regions containing members of nuclear factor- $\kappa(\mathrm{NF} \kappa \mathrm{B})$ signaling. Particularly, gains of 2p15-16 were found and confirmed by FISH in three cases and were associated with breakpoints at the REL locus. Nuclear expression (i.e., activation) of the encoded REL protein was then documented by immunohistochemistry. These findings were in line with what previously observed by gene expression profiling in PTCL/NOS and with the general notion that $\mathrm{NF \kappa B}$ is activated in a fraction of cases with possible prognostic impact [83-86]. Further, recurrent genomic imbalances appeared to affect and genes involved in cell cycle control such as $R B 1, T P 53, C D K 6$ and $C D K N 2 A$-B (Table 5) [81]. 
Table 5. The most important recurrent genetic aberrations in Peripheral $\mathrm{T}$ cell lymphomas (PTCLs).

\begin{tabular}{cccc}
\hline Location & Alteration & Candidate Genes & References \\
\hline $2 \mathrm{p} 15$ & Gain & $R E L$ & {$[81]$} \\
$6 \mathrm{q} 21$ & Loss & $P R D M 1$ & {$[82]$} \\
$7 \mathrm{q} 21$ & Gain & $C D K 6$ & {$[81]$} \\
$8 \mathrm{q} 24$ & Gain & $E I F 3 H$ & {$[80,81]$} \\
$9 \mathrm{p} 21$ & Loss & $C D K N 2 A, C D K N 2 B, M T A P$ & {$[80,81]$} \\
$9 \mathrm{p} 23$ & Gain & - & {$[80]$} \\
$10 \mathrm{p} 11$ & Loss & ZEB1, ARHGAP12, KIF5B,EPC1,CCDC7 & {$[81]$} \\
$13 \mathrm{q} 14$ & Loss & $R B 1$ & {$[81]$} \\
$17 \mathrm{p} 11$ & Loss & - & {$[81]$} \\
$17 \mathrm{p} 13$ & Loss & $T P 53$ & {$[81,82]$} \\
$19 \mathrm{q} 13$ & Gain & - & {$[80]$} \\
\hline
\end{tabular}

More recently, a high-density SNPs array was applied to a series of 64 ALCLs [82], the third most common nodal PTCL subtype. The authors found that the commonest lesions were losses at $17 \mathrm{p} 13$ and at 6q21, encompassing the TP53 and PRDM1 genes, respectively. The latter gene, encoding for BLIMP1, was inactivated by multiple mechanisms, more frequently, but not exclusively, in ALK-negative/ALCL. In vitro and in vivo experiments showed that that PRDM1 is a tumor suppressor gene in ALCL models, likely acting as an anti-apoptotic agent. Losses of TP53 and/or PRDM1 were present in 52\% of ALK-negative/ALCL, and in $29 \%$ of all ALCL cases. Of clinical relevance, the group of patients with ALK-negative/ALCL and bearing PRDMI and/or 17p loss presented an inferior overall survival [82].

\section{Conclusions}

With the advent of SNP arrays, a large number of genetic abnormalities have been described. This is mainly a result of its improved resolution compared to the more traditional methods like CGH and FISH. The newly discovered genetic alterations, such as CNVs and LOHs, have improved our understanding of the pathology of different human tumors, as well as provided us with new markers for diagnosis and therapy selection [11-16]. However, as any other technique, it has its own limitations; particularly, the lack of possibility for detecting inversions and balanced chromosomal translocations and the need, if optimal results are aimed, for normal matched DNA, has largely limited an extensive clinical application so far. However, a combination of SNP array along with other techniques such as FISH has often been accommodated [87,88]. Currently, NGS-based approaches are overcoming the limits of SNP arrays and cytogenetic technologies. SNP arrays, however, probably will continue to be used in diagnosis, as they offer more economic possibilities when compared to the current NGS options [88-90].

\section{Acknowledgments}

This work was supported by the Centro Interdipartimentale per la Ricerca sul Cancro "G. Prodi", BolognAIL, AIRC IG 2013 N.14355-Piccaluga, RFO (Piccaluga), Progetto Strategico di Ateneo 2006 (Piccaluga), and FIRB Futura 2011 RBFR12D1CB (Piccaluga). 


\section{Author Contributions}

Maryam Etebari, Mohsen Navari and Pier Paolo Piccaluga collected and reviewed literature and wrote the article.

\section{Conflicts of Interest}

The authors declare no conflict of interest.

\section{References}

1. Skibola, C.F.; Bracci, P.M.; Halperin, E.; Conde, L.; Craig, D.W.; Agana, L.; Iyadurai, K.; Becker, N.; Brooks-Wilson, A.; Curry, J.D.; et al. Genetic variants at 6p21.33 are associated with susceptibility to follicular lymphoma. Nat. Genet. 2009, 41, 873-875.

2. Lenz, G.; Staudt, L.M. Aggressive lymphomas. N. Engl. J. Med. 2010, 362, 1417-1429.

3. Jhanwar, S.C.; Denley, R.C. Genetic abnormalities in non-Hodgkin's lymphoma as revealed by conventional and molecular cytogenetics methods of analyses. Methods Mol. Biol. 2011, 730, 131-148.

4. De Leeuw, N.; Hehir-Kwa, J.Y.; Simons, A.; Geurts van Kessel, A.; Smeets, D.F.; Faas, B.H.; Pfundt, R. SNP array analysis in constitutional and cancer genome diagnostics - Copy number variants, genotyping and quality control. Cytogenet. Genome Res. 2011, 135, 212-221

5. Deng, L.; Peng, Y.; Liu, J.; Wen, J.; Xia, Y.; Liang, D.; Wu, L. Brief report adult patient presenting an interstitial (9) (q21.32q31.1) direct duplication resulting from the malsegregation of a paternal balanced insertional translocation. Birth Defects Res. A Clin. Mol. Teratol. 2014, 100, 294-299.

6. Karampetsou, E.; Morrogh, D.; Chitty, L. Microarray technology for the diagnosis of fetal chromosomal aberrations: Which platform should we use? J. Clin. Med. 2014, 3, 663-678.

7. Bacolod, M.D.; Barany, F. Molecular profiling of colon tumors: The search for clinically relevant biomarkers of progression, prognosis, therapeutics, and predisposition. Ann. Surg. Oncol. 2011, 18, 3694-3700.

8. Malek, S. Molecular biomarkers in chronic lymphocytic leukemia. Adv. Exp. Med. Biol. 2013, 792, 193-214.

9. Costantini, M.; Clay, O.; Federico, C.; Saccone, S.; Auletta, F.; Bernardi, G. Human chromosomal bands: Nested structure, high-definition map and molecular basis. Chromosoma 2007, 116, 29-40.

10. Najfeld, V. Diagnostic application of FISH to hematological malignancies. Cancer Investig. 2003, 21, 807-814.

11. Kallioniemi, A.; Kallioniemi, O.P.; Sudar, D.; Rutovitz, D.; Gray, J.W.; Waldman, F.; Pinkel, D. Comparative genomic hybridization for molecular cytogenetic analysis of solid tumors. Science 1992, 258, 818-821.

12. Pinkel, D.; Albertson, D.G. Comparative genomic hybridization. Ann. Rev. Genom. Hum. Genet. 2005, 6, 331-354. 
13. Sellick, G.S.; Longman, C.; Tolmie, J.; Newbury-Ecob, R.; Geenhalgh, L.; Hughes, S.; Whiteford, M.; Garrett, C.; Houlston, R.S. Genomewide linkage searches for Mendelian disease loci can be efficiently conducted using high-density SNP genotyping arrays. Nucleic Acids Res. 2004, 32, doi:10.1093/nar/gnh163.

14. Iacobucci, I.; Lonetti, A.; Papayannidis, C.; Martinelli, G. Use of single nucleotide polymorphism array technology to improve the identification of chromosomal lesions in leukemia. Curr. Cancer Drug Targets 2013, 13, 791-810.

15. Gowda, C.; Dovat, S. Genetic targets in pediatric acute lymphoblastic leukemia. Adv. Exp. Med. Biol. 2013, 779, 327-340.

16. Sato-Otsubo, A.; Sanada, M.; Ogawa, S. Single-nucleotide polymorphism array karyotyping in clinical practice: Where, when, and how? Semin. Oncol. 2012, 39, 13-25.

17. Dougherty, M.J.; Wilmoth, D.M.; Tooke, L.S.; Shaikh, T.H.; Gai, X.; Hakonarson, H.; Biegel, J.A. Implementation of high resolution single nucleotide polymorphism array analysis as a clinical test for patients with hematologic malignancies. Cancer Genet. 2011, 204, 26-38.

18. Simons, A.; Sikkema-Raddatz, B.; de Leeuw, N.; Konrad, N.C.; Hastings, R.J.; Schoumans, J. Genome-wide arrays in routine diagnostics of hematological malignancies. Hum. Mutat. 2012, 33, 941-948.

19. LaFramboise, T. Single nucleotide polymorphism arrays: A decade of biological, computational and technological advances. Nucleic Acids Res. 2009, 37, 4181-4193.

20. Pounds, S.; Cheng, C.; Mullighan, C.; Raimondi, S.C.; Shurtleff, S.; Downing, J.R. Reference alignment of SNP microarray signals for copy number analysis of tumors. Bioinformatics 2009, 25, 315-321.

21. Arteaga-Salas, J.M.; Zuzan, H.; Langdon, W.B.; Upton, G.J.; Harrison, A.P. An overview of image-processing methods for Affymetrix GeneChips. Brief. Bioinform. 2008, 9, 25-33.

22. Sebat, J.; Lakshmi, B.; Troge, J.; Alexander, J.; Young, J.; Lundin, P.; Maner, S.; Massa, H.; Walker, M.; Chi, M.; et al. Large-scale copy number polymorphism in the human genome. Science 2004, 305, 525-528.

23. Iafrate, A.J.; Feuk, L.; Rivera, M.N.; Listewnik, M.L.; Donahoe, P.K.; Qi, Y.; Scherer, S.W.; Lee, C. Detection of large-scale variation in the human genome. Nat. Genet. 2004, 36, 949-951.

24. Rovelet-Lecrux, A.; Hannequin, D.; Raux, G.; Le Meur, N.; Laquerriere, A.; Vital, A.; Dumanchin, C.; Feuillette, S.; Brice, A.; Vercelletto, M.; et al. APP locus duplication causes autosomal dominant early-onset Alzheimer disease with cerebral amyloid angiopathy. Nat. Genet. 2006, 38, 24-26.

25. Fellermann, K.; Stange, D.E.; Schaeffeler, E.; Schmalzl, H.; Wehkamp, J.; Bevins, C.L.; Reinisch, W.; Teml, A.; Schwab, M.; Lichter, P.; et al. A chromosome 8 gene-cluster polymorphism with low human $\beta$-defensin 2 gene copy number predisposes to Crohn disease of the colon. Am. J. Hum. Genet. 2006, 79, 439-448.

26. Sebat, J.; Lakshmi, B.; Malhotra, D.; Troge, J.; Lese-Martin, C.; Walsh, T.; Yamrom, B.; Yoon, S.; Krasnitz, A.; Kendall, J.; et al. Strong association of de novo copy number mutations with autism. Science 2007, 316, 445-449.

27. Hollox, E.J.; Huffmeier, U.; Zeeuwen, P.L.; Palla, R.; Lascorz, J.; Rodijk-Olthuis, D.; van de Kerkhof, P.C.; Traupe, H.; de Jongh, G.; den Heijer, M.; et al. Psoriasis is associated with increased $\beta$-defensin genomic copy number. Nat. Genet. 2008, 40, 23-25. 
28. Simon-Sanchez, J.; Singleton, A. Genome-wide association studies in neurological disorders. Lancet Neurol. 2008, 7, 1067-1072.

29. Walsh, T.; McClellan, J.M.; McCarthy, S.E.; Addington, A.M.; Pierce, S.B.; Cooper, G.M.; Nord, A.S.; Kusenda, M.; Malhotra, D.; Bhandari, A.; et al. Rare structural variants disrupt multiple genes in neurodevelopmental pathways in schizophrenia. Science 2008, 320, 539-543.

30. O'Keefe, C.; McDevitt, M.A.; Maciejewski, J.P. Copy neutral loss of heterozygosity: A novel chromosomal lesion in myeloid malignancies. Blood 2010, 115, 2731-2739.

31. Zheng, H.T.; Peng, Z.H.; Li, S.; He, L. Loss of heterozygosity analyzed by single nucleotide polymorphism array in cancer. World J. Gastroenterol. 2005, 11, 6740-6744.

32. Maciejewski, J.P.; Mufti, G.J. Whole genome scanning as a cytogenetic tool in hematologic malignancies. Blood 2008, 112, 965-974.

33. Murthy, S.K.; DiFrancesco, L.M.; Ogilvie, R.T.; Demetrick, D.J. Loss of heterozygosity associated with uniparental disomy in breast carcinoma. Mod. Pathol. 2002, 15, 1241-1250.

34. Tuna, M.; Ju, Z.; Smid, M.; Amos, C.I.; Mills, G.B. Prognostic relevance of acquired uniparental disomy in serous ovarian cancer. Mol. Cancer 2015, 14, doi:10.1186/s12943-015-0289-1.

35. Rosenwald, A.; Wright, G.; Chan, W.C.; Connors, J.M.; Campo, E.; Fisher, R.I.; Gascoyne, R.D.; Muller-Hermelink, H.K.; Smeland, E.B.; Giltnane, J.M.; et al. The use of molecular profiling to predict survival after chemotherapy for diffuse large-B-cell lymphoma. N. Engl. J. Med. 2002, 346, 1937-1947.

36. Wessendorf, S.; Schwaenen, C.; Kohlhammer, H.; Kienle, D.; Wrobel, G.; Barth, T.F.; Nessling, M.; Moller, P.; Dohner, H.; Lichter, P.; et al. Hidden gene amplifications in aggressive B-cell non-Hodgkin lymphomas detected by microarray-based comparative genomic hybridization. Oncogene 2003, 22, 1425-1429.

37. Morin, R.D.; Mungall, K.; Pleasance, E.; Mungall, A.J.; Goya, R.; Huff, R.D.; Scott, D.W.; Ding, J.; Roth, A.; Chiu, R.; et al. Mutational and structural analysis of diffuse large B-cell lymphoma using whole-genome sequencing. Blood 2013, 122, 1256-1265.

38. Monti, S.; Chapuy, B.; Takeyama, K.; Rodig, S.J.; Hao, Y.; Yeda, K.T.; Inguilizian, H.; Mermel, C.; Currie, T.; Dogan, A.; et al. Integrative analysis reveals an outcome-associated and targetable pattern of p53 and cell cycle deregulation in diffuse large B cell lymphoma. Cancer Cell 2012, 22, 359-372.

39. Pasqualucci, L.; Trifonov, V.; Fabbri, G.; Ma, J.; Rossi, D.; Chiarenza, A.; Wells, V.A.; Grunn, A.; Messina, M.; Elliot, O.; et al. Analysis of the coding genome of diffuse large B-cell lymphoma. Nat. Genet. 2011, 43, 830-837.

40. Green, M.R.; Aya-Bonilla, C.; Gandhi, M.K.; Lea, R.A.; Wellwood, J.; Wood, P.; Marlton, P.; Griffiths, L.R. Integrative genomic profiling reveals conserved genetic mechanisms for tumorigenesis in common entities of non-Hodgkin's lymphoma. Genes Chromosom. Cancer 2011, 50, 313-326.

41. Scandurra, M.; Mian, M.; Greiner, T.C.; Rancoita, P.M.; De Campos, C.P.; Chan, W.C.; Vose, J.M.; Chigrinova, E.; Inghirami, G.; Chiappella, A.; et al. Genomic lesions associated with a different clinical outcome in diffuse large B-Cell lymphoma treated with R-CHOP-21. Br. J. Haematol. 2010, 151, 221-231. 
42. Scholtysik, R.; Kreuz, M.; Hummel, M.; Rosolowski, M.; Szczepanowski, M.; Klapper, W.; Loeffler, M.; Trumper, L.; Siebert, R.; Kuppers, R.; et al. Characterization of genomic imbalances in diffuse large B-cell lymphoma by detailed SNP-chip analysis. Int. J. Cancer 2015, 136, 1033-1042.

43. Scholtysik, R.; Nagel, I.; Kreuz, M.; Vater, I.; Giefing, M.; Schwaenen, C.; Wessendorf, S.; Trumper, L.; Loeffler, M.; Siebert, R.; et al. Recurrent deletions of the TNFSF7 and TNFSF9 genes in 19p13.3 in diffuse large B-cell and Burkitt lymphomas. Int. J. Cancer 2012, 131, E830-E835.

44. Takeyama, K.; Monti, S.; Manis, J.P.; Dal Cin, P.; Getz, G.; Beroukhim, R.; Dutt, S.; Aster, J.C.; Alt, F.W.; Golub, T.R.; et al. Integrative analysis reveals 53BP1 copy loss and decreased expression in a subset of human diffuse large B-cell lymphomas. Oncogene 2008, 27, 318-322.

45. Lenz, G.; Wright, G.W.; Emre, N.C.; Kohlhammer, H.; Dave, S.S.; Davis, R.E.; Carty, S.; Lam, L.T.; Shaffer, A.L.; Xiao, W.; et al. Molecular subtypes of diffuse large B-cell lymphoma arise by distinct genetic pathways. Proc. Natl. Acad. Sci. USA 2008, 105, 13520-13525.

46. Aya-Bonilla, C.; Green, M.R.; Camilleri, E.; Benton, M.; Keane, C.; Marlton, P.; Lea, R.; Gandhi, M.K.; Griffiths, L.R. High-resolution loss of heterozygosity screening implicates PTPRJ as a potential tumor suppressor gene that affects susceptibility to Non-Hodgkin's lymphoma. Genes Chromosom. Cancer 2013, 52, 467-479.

47. Dias, L.M.; Thodima, V.; Friedman, J.; Ma, C.; Guttapalli, A.; Mendiratta, G.; Siddiqi, I.N.; Syrbu, S.; Chaganti, R.S.; Houldsworth, J. Cross-platform assessment of genomic imbalance confirms the clinical relevance of genomic complexity and reveals loci with potential pathogenic roles in diffuse large B-Cell lymphoma. Leuk. Lymphoma 2015, 21, 1-27.

48. Conde, L.; Riby, J.; Zhang, J.; Bracci, P.M.; Skibola, C.F. Copy number variation analysis on a non-hodgkin lymphoma case-control study identifies an 11q25 duplication associated with diffuse large B-cell lymphoma. PLoS ONE 2014, 9, e105382.

49. Jardin, F.; Jais, J.P.; Molina, T.J.; Parmentier, F.; Picquenot, J.M.; Ruminy, P.; Tilly, H.; Bastard, C.; Salles, G.A.; Feugier, P.; et al. Diffuse large B-cell lymphomas with CDKN2A deletion have a distinct gene expression signature and a poor prognosis under R-CHOP treatment: A GELA study. Blood 2010, 116, 1092-1104.

50. Pileri, S.A.; Ascani, S.; Sabattini, E.; Fraternali-Orcioni, G.; Poggi, S.; Piccioli, M.; Piccaluga, P.P.; Gamberi, B.; Zinzani, P.L.; Leoncini, L.; et al. The pathologist's view point. Part I-Indolent lymphomas. Haematologica 2000, 85, 1291-1307.

51. Klein, U.; Dalla-Favera, R. Germinal centres: Role in B-cell physiology and malignancy. Nat. Rev. Immunol. 2008, 8, 22-33.

52. Martinez-Climent, J.A.; Alizadeh, A.A.; Segraves, R.; Blesa, D.; Rubio-Moscardo, F.; Albertson, D.G.; Garcia-Conde, J.; Dyer, M.J.; Levy, R.; Pinkel, D.; et al. Transformation of follicular lymphoma to diffuse large cell lymphoma is associated with a heterogeneous set of DNA copy number and gene expression alterations. Blood 2003, 101, 3109-3117.

53. Piccaluga, P.P.; Califano, A.; Klein, U.; Agostinelli, C.; Bellosillo, B.; Gimeno, E.; Serrano, S.; Sole, F.; Zang, Y.; Falini, B.; et al. Gene expression analysis provides a potential rationale for revising the histological grading of follicular lymphomas. Haematologica 2008, 93, 1033-1038.

54. Tilly, H.; Rossi, A.; Stamatoullas, A.; Lenormand, B.; Bigorgne, C.; Kunlin, A.; Monconduit, M.; Bastard, C. Prognostic value of chromosomal abnormalities in follicular lymphoma. Blood 1994, 84, 1043-1049. 
55. Leich, E.; Salaverria, I.; Bea, S.; Zettl, A.; Wright, G.; Moreno, V.; Gascoyne, R.D.; Chan, W.C.; Braziel, R.M.; Rimsza, L.M.; et al. Follicular lymphomas with and without translocation $\mathrm{t}(14 ; 18)$ differ in gene expression profiles and genetic alterations. Blood 2009, 114, 826-834.

56. Cheung, K.J.; Delaney, A.; Ben-Neriah, S.; Schein, J.; Lee, T.; Shah, S.P.; Cheung, D.; Johnson, N.A.; Mungall, A.J.; Telenius, A.; et al. High resolution analysis of follicular lymphoma genomes reveals somatic recurrent sites of copy-neutral loss of heterozygosity and copy number alterations that target single genes. Genes Chromosom. Cancer 2010, 49, 669-681.

57. Cheung, K.J.; Rogic, S.; Ben-Neriah, S.; Boyle, M.; Connors, J.M.; Gascoyne, R.D.; Horsman, D.E. SNP analysis of minimally evolved $\mathrm{t}(14 ; 18)(\mathrm{q} 32 ; \mathrm{q} 21)$-positive follicular lymphomas reveals a common copy-neutral loss of heterozygosity pattern. Cytogenet. Genome Res. 2012, 136, 38-43.

58. Cheung, K.J.; Shah, S.P.; Steidl, C.; Johnson, N.; Relander, T.; Telenius, A.; Lai, B.; Murphy, K.P.; Lam, W.; Al-Tourah, A.J.; et al. Genome-wide profiling of follicular lymphoma by array comparative genomic hybridization reveals prognostically significant DNA copy number imbalances. Blood 2009, 113, 137-148.

59. Bouska, A.; McKeithan, T.W.; Deffenbacher, K.E.; Lachel, C.; Wright, G.W.; Iqbal, J.; Smith, L.M.; Zhang, W.; Kucuk, C.; Rinaldi, A.; et al. Genome-wide copy-number analyses reveal genomic abnormalities involved in transformation of follicular lymphoma. Blood 2014, 123, 1681-1690.

60. Ross, C.W.; Ouillette, P.D.; Saddler, C.M.; Shedden, K.A.; Malek, S.N. Comprehensive analysis of copy number and allele status identifies multiple chromosome defects underlying follicular lymphoma pathogenesis. Clin. Cancer Res. 2007, 13, 4777-4785.

61. O’Shea, D.; O’Riain, C.; Gupta, M.; Waters, R.; Yang, Y.; Wrench, D.; Gribben, J.; Rosenwald, A.; Ott, G.; Rimsza, L.M.; et al. Regions of acquired uniparental disomy at diagnosis of follicular lymphoma are associated with both overall survival and risk of transformation. Blood 2009, 113, 2298-2301.

62. Fitzgibbon, J.; Iqbal, S.; Davies, A.; O'Shea, D.; Carlotti, E.; Chaplin, T.; Matthews, J.; Raghavan, M.; Norton, A.; Lister, T.A.; et al. Genome-wide detection of recurring sites of uniparental disomy in follicular and transformed follicular lymphoma. Leukemia 2007, 21, 1514-1520.

63. Aubry, J.F.; Cheung, J.; Morin, O.; Beaulieu, L.; Hsu, I.C.; Pouliot, J. Investigation of geometric distortions on magnetic resonance and cone beam computed tomography images used for planning and verification of high-dose rate brachytherapy cervical cancer treatment. Brachytherapy 2010, 9 , 266-273.

64. Furtado, M.; Rule, S. Indolent mantle cell lymphoma. Haematologica 2011, 96, 1086-1088.

65. Ondrejka, S.L.; Lai, R.; Smith, S.D.; Hsi, E.D. Indolent mantle cell leukemia: A clinicopathological variant characterized by isolated lymphocytosis, interstitial bone marrow involvement, $\kappa$ light chain restriction, and good prognosis. Haematologica 2011, 96, 1121-1127.

66. Lovec, H.; Grzeschiczek, A.; Kowalski, M.B.; Moroy, T. Cyclin D1/bcl-1 cooperates with MYC genes in the generation of B-cell lymphoma in transgenic mice. EMBO J. 1994, 13, 3487-3495.

67. Hirt, C.; Schuler, F.; Dolken, L.; Schmidt, C.A.; Dolken, G. Low prevalence of circulating $\mathrm{t}(11 ; 14)(\mathrm{q} 13 ; \mathrm{q} 32)$-positive cells in the peripheral blood of healthy individuals as detected by real-time quantitative PCR. Blood 2004, 104, 904-905. 
68. Fernandez, V.; Salamero, O.; Espinet, B.; Sole, F.; Royo, C.; Navarro, A.; Camacho, F.; Bea, S.; Hartmann, E.; Amador, V.; et al. Genomic and gene expression profiling defines indolent forms of mantle cell lymphoma. Cancer Res. 2010, 70, 1408-1418.

69. Royo, C.; Salaverria, I.; Hartmann, E.M.; Rosenwald, A.; Campo, E.; Bea, S. The complex landscape of genetic alterations in mantle cell lymphoma. Semin. Cancer Biol. 2011, 21, 322-334.

70. Salaverria, I.; Zettl, A.; Bea, S.; Moreno, V.; Valls, J.; Hartmann, E.; Ott, G.; Wright, G.; Lopez-Guillermo, A.; Chan, W.C.; et al. Specific secondary genetic alterations in mantle cell lymphoma provide prognostic information independent of the gene expression-based proliferation signature. J. Clin. Oncol. 2007, 25, 1216-1222.

71. Setoodeh, R.; Schwartz, S.; Papenhausen, P.; Zhang, L.; Sagatys, E.M.; Moscinski, L.C.; Shao, H. Double-hit mantle cell lymphoma with $M Y C$ gene rearrangement or amplification: A report of four cases and review of the literature. Int. J. Clin. Exp. Pathol. 2013, 6, 155-167.

72. Rubio-Moscardo, F.; Climent, J.; Siebert, R.; Piris, M.A.; Martin-Subero, J.I.; Nielander, I.; Garcia-Conde, J.; Dyer, M.J.; Terol, M.J.; Pinkel, D.; et al. Mantle-cell lymphoma genotypes identified with $\mathrm{CGH}$ to BAC microarrays define a leukemic subgroup of disease and predict patient outcome. Blood 2005, 105, 4445-4454.

73. Kawamata, N.; Ogawa, S.; Gueller, S.; Ross, S.H.; Huynh, T.; Chen, J.; Chang, A.; Nabavi-Nouis, S.; Megrabian, N.; Siebert, R.; et al. Identified hidden genomic changes in mantle cell lymphoma using high-resolution single nucleotide polymorphism genomic array. Exp. Hematol. 2009, 37, 937-946.

74. Rinaldi, A.; Mian, M.; Chigrinova, E.; Arcaini, L.; Bhagat, G.; Novak, U.; Rancoita, P.M.; De Campos, C.P.; Forconi, F.; Gascoyne, R.D.; et al. Genome-wide DNA profiling of marginal zone lymphomas identifies subtype-specific lesions with an impact on the clinical outcome. Blood 2011, 117, 1595-1604.

75. Flossbach, L.; Holzmann, K.; Mattfeldt, T.; Buck, M.; Lanz, K.; Held, M.; Moller, P.; Barth, T.F. High-resolution genomic profiling reveals clonal evolution and competition in gastrointestinal marginal zone B-cell lymphoma and its large cell variant. Int. J. Cancer 2013, 132, E116-E127.

76. Takahashi, H.; Usui, Y.; Ueda, S.; Yamakawa, N.; Sato-Otsubo, A.; Sato, Y.; Ogawa, S.; Goto, H. Genome-wide analysis of ocular adnexal lymphoproliferative disorders using high-resolution single nucleotide polymorphism array. Investig. Ophthalmol. Vis. Sci. 2015, 56, 4156-4165.

77. Pileri, S.A.; Piccaluga, P.P. New molecular insights into peripheral T cell lymphomas. J. Clin. Investig. 2012, 122, 3448-3455.

78. Piccaluga, P.P.; Tabanelli, V.; Pileri, S.A. Molecular genetics of peripheral T-cell lymphomas. Int. J. Hematol. 2014, 99, 219-226.

79. Agostinelli, C.; Piccaluga, P.P.; Went, P.; Rossi, M.; Gazzola, A.; Righi, S.; Sista, T.; Campidelli, C.; Zinzani, P.L.; Falini, B.; et al. Peripheral T cell lymphoma, not otherwise specified: The stuff of genes, dreams and therapies. J. Clin. Pathol. 2008, 61, 1160-1167.

80. Fujiwara, S.I.; Yamashita, Y.; Nakamura, N.; Choi, Y.L.; Ueno, T.; Watanabe, H.; Kurashina, K.; Soda, M.; Enomoto, M.; Hatanaka, H.; et al. High-resolution analysis of chromosome copy number alterations in angioimmunoblastic T-cell lymphoma and peripheral T-cell lymphoma, unspecified, with single nucleotide polymorphism-typing microarrays. Leukemia 2008, 22, 1891-1898. 
81. Hartmann, S.; Gesk, S.; Scholtysik, R.; Kreuz, M.; Bug, S.; Vater, I.; Doring, C.; Cogliatti, S.; Parrens, M.; Merlio, J.P.; et al. High resolution SNP array genomic profiling of peripheral T cell lymphomas, not otherwise specified, identifies a subgroup with chromosomal aberrations affecting the REL locus. Br. J. Haematol. 2010, 148, 402-412.

82. Boi, M.; Rinaldi, A.; Kwee, I.; Bonetti, P.; Todaro, M.; Tabbo, F.; Piva, R.; Rancoita, P.M.; Matolcsy, A.; Timar, B.; et al. PRDM1/BLIMP1 is commonly inactivated in anaplastic large T-cell lymphoma. Blood 2013, 122, 2683-2693.

83. Martinez-Delgado, B.; Cuadros, M.; Honrado, E.; Ruiz de la Parte, A.; Roncador, G.; Alves, J.; Castrillo, J.M.; Rivas, C.; Benitez, J. Differential expression of NF-kB pathway genes among peripheral T-cell lymphomas. Leukemia 2005, 19, 2254-2263.

84. Piccaluga, P.P.; Agostinelli, C.; Califano, A.; Rossi, M.; Basso, K.; Zupo, S.; Went, P.; Klein, U.; Zinzani, P.L.; Baccarani, M.; et al. Gene expression analysis of peripheral T cell lymphoma, unspecified, reveals distinct profiles and new potential therapeutic targets. J. Clin. Investig. 2007, $117,823-834$.

85. Piccaluga, P.P.; Agostinelli, C.; Califano, A.; Carbone, A.; Fantoni, L.; Ferrari, S.; Gazzola, A.; Gloghini, A.; Righi, S.; Rossi, M.; et al. Gene expression analysis of angioimmunoblastic lymphoma indicates derivation from $\mathrm{T}$ follicular helper cells and vascular endothelial growth factor deregulation. Cancer Res. 2007, 67, 10703-10710.

86. Odqvist, L.; Sanchez-Beato, M.; Montes-Moreno, S.; Martin-Sanchez, E.; Pajares, R.; Sanchez-Verde, L.; Ortiz-Romero, P.L.; Rodriguez, J.; Rodriguez-Pinilla, S.M.; Iniesta-Martinez, F.; et al. NIK controls classical and alternative NF- $\mathrm{KB}$ activation and is necessary for the survival of human T-cell lymphoma cells. Clin. Cancer Res. 2013, 19, 2319-2330.

87. Mao, X.; Young, B.D.; Lu, Y.J. The application of single nucleotide polymorphism microarrays in cancer research. Curr. Genomics 2007, 8, 219-228.

88. Srebniak, M.I.; Boter, M.; Oudesluijs, G.O.; Cohen-Overbeek, T.; Govaerts, L.C.; Diderich, K.E.; Oegema, R.; Knapen, M.F.; van de Laar, I.M.; Joosten, M.; et al. Genomic SNP array as a gold standard for prenatal diagnosis of foetal ultrasound abnormalities. Mol. Cytogenet. 2012, 5, doi:10.1186/1755-8166-5-14.

89. Kumar, S.; Banks, T.W.; Cloutier, S. SNP Discovery through next-generation sequencing and its applications. Int. J. Plant Genomics 2012, 2012, doi:10.1155/2012/831460.

90. Nielsen, R.; Paul, J.S.; Albrechtsen, A.; Song, Y.S. Genotype and SNP calling from next-generation sequencing data. Nat. Rev. Genet. 2011, 12, 443-451.

(C) 2015 by the authors; licensee MDPI, Basel, Switzerland. This article is an open access article distributed under the terms and conditions of the Creative Commons Attribution license (http://creativecommons.org/licenses/by/4.0/). 